\title{
Relationship of variable chlorophyll fluorescence indices to photosynthetic rates in microphytobenthos
}

\author{
João Serôdio*, Sónia Vieira, Filipe Barroso \\ Departamento de Biologia \& CESAM - Centro de Estudos do Ambiente e do Mar, Universidade de Aveiro, \\ Campus de Santiago, 3810-193 Aveiro, Portugal
}

\begin{abstract}
The present study investigated the use of indices based on variable chlorophyll fluorescence for the estimation of rates of photosynthesis by microphytobenthos. The relationship between fluorescence indices and photosynthesis, as measured on intact sediment samples, was studied (1) theoretically, using a simulation model to analyse the effects of light attenuation, biomass profile and depth integration, and (2) experimentally, by obtaining a comprehensive dataset of paired measurements of photosynthesis (oxygen microsensors) and fluorescence (PAM fluorometry) along hourly, $14 \mathrm{~d}$ and seasonal time scales, at 2 estuarine intertidal sites with distinctive sediment characteristics. Depth-integrated photosynthesis $(P)$ was compared to EFY, an index based on depthintegrated fluorescence parameters estimating the productive biomass (minimum fluorescence, $F_{0}$ ) and the Photosystem II effective quantum yield $\left(\Delta F / F_{\mathrm{m}}{ }^{\prime}\right)$. Whilst numerical simulations have indicated that the relationship between EFY and $P$ can be conditioned by the vertical distribution of biomass, the experimental data showed EFY to closely trace variations in $P$ in a wide range of light conditions, vertical distribution of productivity, sediment characteristics, and taxonomic composition of the microalgal community. A linear relationship between EFY and $P$ was generally found, both when considering each day separately (significant correlations in $94.3 \%$ of the days) and when different days within each sampling period were pooled together (significant correlations in all cases). The slopes of the regression equations of EFY on $P$ were found to vary throughout the year, indicating that the practical use of the index may require the frequent determination of conversion factors. Nevertheless, the use of this fluorescence index was confirmed to represent a valid methodology for the rapid and non-destructive estimation of photosynthetic rates in microphytobenthos.
\end{abstract}

KEY WORDS: Microphytobenthos $\cdot$ Photosynthesis $\cdot$ PAM fluorescence $\cdot$ Depth integration $\cdot$ Primary production $\cdot$ PSII electron transport $\cdot$ Benthic microalgae $\cdot$ Biofilms

\section{INTRODUCTION}

Microphytobenthos comprises sediment-inhabiting microalgal communities that form highly dense sedimentary biofilms on intertidal flats of estuaries and coastal areas. Most of the scientific interest in microphytobenthos has been driven by the increasing recognition of its importance for primary production, being considered one of the major contributors to ecosystemlevel productivity of estuaries and shallow coastal waters (Underwood \& Kromkamp 1999). However, despite the large number of studies, the question as to which methodology is optimal for measuring micro- phytobenthos productivity remains open (Perkins et al. 2002, Forster \& Kromkamp 2004). Several methods have been applied, most originally developed for phytoplankton, but no single technique has emerged as consensual to best cope with the various difficulties that affect the measurement of the photosynthetic activity of microalgal biofilms under natural conditions (Serôdio 2003). The quantification of microphytobenthos productivity presents a number of specific aspects that confound the direct application of methods developed and routinely used for other photoautotrophs: (1) the small vertical scale of the photic zone of the sediment and the steep physico-chemical gradients that 
are formed therein; (2) the need for preservation of the microenvironment of the photic zone during measurements, as it determines the photosynthetic activity of the microalgae; (3) the highly dynamic intertidal environment and the changeable conditions that control microalgal photosynthesis, both of external (fluctuations in light, temperature, or salinity, imposed by solar and tidal cycles) and endogenous origin (changes in biofilm biomass and composition due to vertical migration); (4) the occurrence of non-photosynthetic and non-biological processes in sediments that affect carbon or oxygen fluxes, thus confounding techniques based on the measurement of these elements; (5) the high horizontal heterogeneity, on spatial scales from micrometres to metres.

The introduction of pulse amplitude modulation (PAM) (Schreiber et al. 1986) fluorometry to the study of the photosynthetic activity of microphytobenthos (Hartig et al. 1998, Kromkamp et al. 1998) enabled some of these difficulties to be overcome, as it made it possible to obtain photosynthesis-specific data (on the operating efficiency of Photosystem II, PSII), in a noninvasive and virtually instantaneous way. Moreover, the same methodology provided a way to quantify the microalgal biomass contributing to community-level photosynthesis (productive biomass) (Serôdio et al. 1997, 2001). Together with irradiance and the efficiency of light energy use, productive biomass was found to represent a major source of short-term variability in microphytobenthos productivity (Serôdio et al. 2001). This is largely due to the vertical migration of the dominant motile diatoms, which causes the variation of the cell concentration in the photic zone of the sediment during daytime low tide periods. Because of the comparable dimensions of the depth of the photic zone (max. 400 to $500 \mu \mathrm{m}$ ) and of the diatom cells (typically ca. $50 \mu \mathrm{m})$, vertical cell movements cause large and rapid variations in the fraction of downwelling irradiance that is intercepted and used for photosynthesis.

Considering these sources of variability and the potential of PAM fluorometry to measure both PSII effective quantum efficiency and productive biomass, a fluorescence index was proposed as a proxy for photosynthetic rates of undisturbed microphytobenthos assemblages (Serôdio 2003). This index was found to correlate well with gross rates of photosynthesis as measured on undisturbed samples using oxygen microsensors. However, this result was based on relatively limited experimental evidence, consisting of a dataset obtained for a single sampling site and a few measurements during daily and tidal cycles. On the other hand, modelling studies have recently demonstrated the existence of important discrepancies between depth-integrated fluorescence indices measured on intact microphytobenthos samples and the inherent PSII quantum yield of microalgae that form the biofilm (Forster \& Kromkamp 2004, Serôdio 2004). These are caused by the vertical attenuation of light within the sample and by the depth integration of fluorescence emission, being therefore likely to affect the relationship between depth-integrated photosynthesis and fluorescence indices, a question not investigated in previous studies.

The present study addresses the relationship between fluorescence-based indices and photosynthesis as measured on intact microphytobenthos samples through: (1) the theoretical analysis of the effects of depth integration on photosynthesis and fluorescence emission, including the role of light attenuation, vertical distribution of microalgal biomass, and depth integration of fluorescence, and (2) the measurement and analysis of a comprehensive dataset of paired measurements of photosynthesis and fluorescence, collected at sites with distinctive sediment characteristics and biofilm taxonomic composition, along hourly, $14 \mathrm{~d}$ and seasonal time scales.

\section{MATERIALS AND METHODS}

Theoretical background. The theoretical aspects of the relationship between fluorescence-based indices and photosynthesis as measured on undisturbed microphytobenthos samples were studied by quantifying the effects of light attenuation and depth integration of fluorescence and photosynthesis measurements. This was done by comparing light-response curves of photosynthesis and of fluorescence indices computed from inherent physiological and from depthintegrated parameters.

Photosynthesis: Steady-state photosynthesis at depth $z$ may be parameterised as:

$$
P_{Z}(E)=E_{Z} a^{*}{ }_{\mathrm{PAR}, Z} C_{Z} \phi P_{Z}(E)
$$

where $E_{\mathrm{z}}=E \mathrm{e}^{-k_{\mathrm{P} z}}$, and $E$ is the incident photosynthetically active irradiance (PAR) at the surface, $a^{*}{ }_{\text {PAR }}$ is the chlorophyll (chl)-specific absorption coefficient for PAR, $C$ is the chl a concentration, $\phi P$ is the quantum yield of photosynthesis, and $k_{\mathrm{P}}$ is the diffuse attenuation coefficient for downwelling PAR within the sediment (Table 1). The photosynthetic rate of the whole microphytobenthos assemblage is calculated by integrating $P_{\mathrm{z}}$ over depth between the surface and depth $\mathrm{Z}_{\mathrm{P}}$, below which the rate of photosynthesis becomes undetectable (Serôdio et al. 2001):

$$
P(E)=\int_{0}^{z_{\mathrm{P}}} E a^{*}{ }_{\mathrm{PAR}, z} C_{z} \phi P_{z}\left(E_{z}\right) \mathrm{e}^{-k_{\mathrm{P}} z} \mathrm{~d} z
$$

Fluorescence: Under surface ambient irradiance $E_{\text {, }}$ the steady-state fluorescence emission at each depth $Z$ may be calculated considering that: 
Table 1. Definition of parameters for measuring photosynthesis and fluorescence on microphytobenthos. PAR: photosynthetically active irradiance; PSII: Photosystem II

\begin{tabular}{|c|c|}
\hline Parameter & Definition \\
\hline$a^{*}{ }_{\mathrm{PAR}}, a^{*}{ }_{\mathrm{ML}}$ & Chl a-specific absorption cross-section of PAR and of measuring light $\left(\mathrm{m}^{2} \mathrm{mg}^{-1} \mathrm{chl} a\right)$ \\
\hline & Chl a concentration $\left(\mathrm{mg} \mathrm{chl} \mathrm{a} \mathrm{m}^{-3}\right)$ \\
\hline $\mathrm{d}$ & Subscript denoting a depth-integrated parameter \\
\hline$\Delta F / F_{\mathrm{m}}{ }^{\prime}$ & Effective quantum yield of PSII (dimensionless) \\
\hline$E, E_{\mathrm{ML}}$ & Spectrally averaged ambient PAR (400-700 $\mathrm{nm}$ ) and measuring irradiance ( $\mu \mathrm{mol}$ quanta $\mathrm{m}^{-2} \mathrm{~s}^{-1}$ ) \\
\hline EF & Fluorescence-based index used as proxy for $P\left(=E \times F_{0}\right)$ (arbitrary units) \\
\hline EFY & Fluorescence-based index used as proxy for $P\left(=E \times F_{0} \times \Delta F / F_{m}^{\prime}\right)$ (arbitrary units) \\
\hline ETR & Relative electron transport rate $\left(=E \times \Delta F / F_{\mathrm{m}}^{\prime}\right)$ (dimensionless) \\
\hline$F_{\mathrm{s}}, F_{\mathrm{m}}{ }^{\prime}$ & Steady-state and maximum fluorescence emitted by a light-adapted sample (fluorescence units) \\
\hline$F_{0}, F_{\mathrm{m}}$ & $\begin{array}{l}\text { Minimum and maximum fluorescence emitted by a dark-adapted sample, measured after } 5 \text { min of darkness } \\
\text { (fluorescence units) }\end{array}$ \\
\hline$F_{0}{ }^{t}, F_{\mathrm{m}}{ }^{t}$ & $\begin{array}{l}\text { Minimum and maximum fluorescence emitted by a dark-adapted sample, measured after } t \text { min of darkness } \\
\text { (fluorescence units) }\end{array}$ \\
\hline$\phi F, \phi P$ & 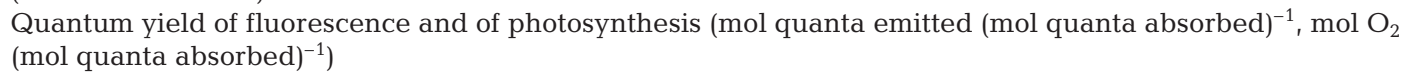 \\
\hline$G$ & $\begin{array}{l}\text { Conversion factor between emitted fluorescence and arbitrary fluorescence units (fluorescence units (quanta } \\
\left.\text { emitted } \mathrm{m}^{-2} \mathrm{~s}^{-1}\right)^{-1} \text { ) }\end{array}$ \\
\hline$k_{\mathrm{P}}, k_{\mathrm{ML}}, k_{F}$ & Diffuse attenuation coefficients for PAR, measuring light, and fluorescence $\left(\mathrm{mm}^{-1}\right)$ \\
\hline$P_{Z 1} P$ & Depth-specific and depth-integrated photosynthetic rate $\left(\mathrm{mol} \mathrm{O}_{2} \mathrm{~m}^{-3} \mathrm{~s}^{-1}, \mathrm{~mol} \mathrm{O}_{2} \mathrm{~m}^{-2} \mathrm{~s}^{-1}\right)$ \\
\hline$z$ & Depth $(\mathrm{mm})$; subscript denoting a depth-specific parameter \\
\hline$Z_{\mathrm{P}}, Z_{F}$ & Maximum depth where photosynthesis and fluorescence are measurable (mm) \\
\hline
\end{tabular}

$$
F_{\mathrm{z}}(E)=E_{\mathrm{ML}, \mathrm{Z}} a_{\mathrm{ML}, \mathrm{z}}^{*} C_{z} \phi F_{z}(E) G
$$

where $E_{\mathrm{ML}, \mathrm{z}}=E_{\mathrm{ML}} \mathrm{e}^{-k_{\mathrm{ML}}{ }^{z}}$, and $E_{\mathrm{ML}}$ is the measuring incident irradiance (excitation light used to induce the emission of fluorescence) at the surface, $a^{*}{ }_{\mathrm{ML}}$ is the chlspecific absorption coefficient for measuring light, $\phi F$ is the quantum yield of fluorescence, $k_{\mathrm{ML}}$ is the diffuse attenuation coefficients for downwelling measuring light, and $G$ is a conversion factor between emitted fluorescence and the arbitrary measured fluorescence units (Serôdio 2004). $\phi F$ varies with light exposure, causing the fluorescence emission to vary between 2 extreme values: the dark- or minimum-level $\left(F_{0}\right)$ and the maximum fluorescence $\left(F_{\mathrm{m}}\right)$, any intermediate emission under ambient actinic light being denoted by $F_{\mathrm{s}}$. Through the application of saturating light pulses, PAM fluorometry allows the determination of $F_{\mathrm{m}}$, when applied on dark-adapted samples, and of $F_{\mathrm{m}}$ ', when applied on light-adapted samples. $F_{\mathrm{s}}$ and $F_{\mathrm{m}}$ 'vary with increasing ambient irradiance $E$, reflecting the gradual closure of PSII reaction centres, the rate of which depends on the physiological status of the microalgae and on the environmental and experimental conditions applied. The fluorescence measured at the surface of a microphytobenthos assemblage represents the integration over depth of the fluorescence emitted at each depth $z$ (the rationale for $F_{\mathrm{m}}{ }^{\prime}$ and $F_{\mathrm{m}}{ }^{\prime}, \mathrm{z}$ is similar), and may be given by:

$$
F_{\mathrm{s}}(E)=\int_{0}^{z_{F}} F_{\mathrm{s}, z}\left(E_{z}\right) \mathrm{e}^{-k_{F} z} \mathrm{~d} z
$$

where $z_{F}$ is the maximum depth at which emitted fluorescence is detected at the surface, and $k_{F}$ is the diffuse attenuation coefficient for upwelling fluorescence (integrated over the range of detectable wavelengths) (Serôdio 2004).

Estimation of photosynthetic rates from fluorescence indices: The measurement of $F_{\mathrm{s}}$ and $F_{\mathrm{m}}{ }^{\prime}$ enables the calculation of the effective quantum yield of charge separation at PSII:

$$
\Delta F / F_{\mathrm{m}}^{\prime}(E)=\frac{F_{\mathrm{m}}{ }^{\prime}(E)-F_{\mathrm{s}}(E)}{F_{\mathrm{m}}{ }^{\prime}(E)}
$$

which was established to be closely related to the quantum yield of photosynthesis (Genty et al. 1989). The use of PAM fluorometry to estimate photosynthetic rates of microphytobenthos is based on the linear relationship between the relative electron transport around PSII, given by ETR $=E \times \Delta F / F_{\mathrm{m}}{ }^{\prime}$ (Schreiber et al. 1995a), and the biomass-specific photosynthetic rates verified for diatoms and other groups of algae (Geel et al. 1997, Flameling \& Kromkamp 1998, Hartig et al. 1998, Serôdio et al. 1998, Morris \& Kromkamp 2003). However, because changes in productive biomass represent a major source of shortterm variability of microphytobenthos communitylevel photosynthesis (Serôdio et al. 2001), this factor must be considered in the formulation of fluorescence-based indices. This was done by using $F_{0}$, known to be the fluorescence parameter the least affected by physiological factors and found to vary proportionally to microalgal biomass (Serôdio et al. 
1997, 2001, Honeywill et al. 2002), in an index of the form $\mathrm{EFY}=E \times F_{0} \times \Delta F / F_{\mathrm{m}}{ }^{\prime}$ (Serôdio 2003).

The ideal fluorescence index should integrate vertically the estimate of the photosynthetic rate calculated for each depth, $E F Y_{z}$ considering the vertical distribution of photosynthesis (from vertical profiles of light, biomass and PSII effective quantum yield):

$\mathrm{EFY}_{z, \mathrm{~d}}(E)=\int_{0}^{z_{F}} \operatorname{EFY}_{z}(E) \mathrm{d} z=\int_{0}^{z_{F}} E_{z} F_{0, z} \frac{F_{\mathrm{m}, z}^{\prime}\left(E_{z}\right)-F_{\mathrm{s}, z}\left(E_{z}\right)}{F_{\mathrm{m}, z}^{\prime}\left(E_{z}\right)} \mathrm{d} z$

However, when working with intact sediment samples, both the minimum fluorescence level and the effective PSII quantum yield can only be determined from depthintegrated fluorescence parameters, measured separately at the sediment surface, which lead to the proposal of the index (Serôdio 2003):

$$
\operatorname{EFY}(E)=E F_{0} \frac{F_{\mathrm{m}}^{\prime}(E)-F_{\mathrm{s}}(E)}{F_{\mathrm{m}}^{\prime}(E)}
$$

The use of depth-integrated fluorescence measurements introduces 2 sources of discrepancy between fluorescence-based estimates and photosynthetic rates of intact sediment samples: (1) because $F_{\mathrm{s}}$ and $F_{\mathrm{m}}$ ' vary differently with $E$, and therefore with depth, the relationship between physiological and depth-integrated values will be different for $F_{\mathrm{s}}$ and for $F_{\mathrm{m}}{ }^{\prime}$, causing $\Delta F / F_{\mathrm{m}}{ }^{\prime}(E)$ to differ from the inherent PSII quantum yield of the microalgae composing the biofilm; this question was treated in detail by Forster \& Kromkamp (2004) and Serôdio (2004); (2) the algebraical difference between the depth integration of $F_{0, z} \times \Delta F / F_{\mathrm{m}_{, z}{ }^{\prime}}(E)$ (the integral of a product, Eq. 6) and the product of depth-integrated $F_{0}$ and $\Delta F / F_{\mathrm{m}}{ }^{\prime}(E)$ (the product of integrals, Eq. 7).

Numerical simulations: The vertical profiles of $P_{z}(E)$, $F_{\mathrm{s}, \mathrm{z}}(E)$ and $F_{\mathrm{m}, \mathrm{z}}{ }^{\prime}(E)$ required to compute $P_{\mathrm{d}}(E), \mathrm{EFY}_{z, \mathrm{~d}}(E)$ and $\operatorname{EFY}(E)$ were calculated by converting $P_{z}, F_{\mathrm{s}, z}$ and $F_{\mathrm{m}, z}{ }^{\prime}$ versus $E$ curves into depth profiles considering an exponential attenuation of $E$ within the sediment. For the calculation of the $P$ and EFY versus $E$ curves, published values of the various parameters of Eqs. (1) to (5) were used (Serôdio et al. 2001, Serôdio 2004). Linear interpolation was applied between consecutive values of the $P_{z} F_{\mathrm{s}, z}$ and $F_{\mathrm{m}, z}^{\prime}$ versus $E$ curves. The $P_{1} F_{\mathrm{s}}$ and $F_{\mathrm{m}}{ }^{\prime}$ versus $E$ curves were obtained from published results obtained using cultures of the diatom Phaeodactylum tricornutum (Serôdio et al. 1998). Other published datasets (Geel et al. 1997, Flameling \& Kromkamp 1998, Serôdio et al. 2001, Serôdio 2004) were tested, and the same general results were obtained.

$P, F_{\mathrm{s}}$ and $F_{\mathrm{m}}{ }^{\prime}$ were calculated for vertical profiles chosen to represent 3 different scenarios regarding vertical distribution of microalgal biomass: an homogenous profile (P0), the accumulation of microalgae at the surface (P1) and the downward migration of microal- gae with the formation of a subsurface chl a maximum (P2). Profiles P1 and P2 were selected from published profiles of light-limited rates of photosynthesis (assumed to proportionally follow the profile of chl $a_{\text {; }}$ Serôdio et al. 2001), and were normalised in order to result in the same total amount of chl a between 0 and $400 \mu \mathrm{m}$. Numerical simulations were performed using MathCad 2001 Pro (MathSoft).

Study sites and sampling. Microphytobenthos samples were collected with minimum disturbance on 2 intertidal flats in the Ria de Aveiro, a mesotidal estuary on the west coast of Portugal: Vista Alegre (VA), on the Canal de Ílhavo, and Gafanha da Encarnação (GE), on the Canal de Mira (Fig. 1). Sites were chosen for their distinctive characteristics regarding sediment granulometry, hydrodynamics and freshwater influence. Sites VA and GE are composed of fine muddy sediments $(97 \%$ particles $<63 \mu \mathrm{m})$ and of sandy mud (45.3\% particles between 63 and $125 \mu \mathrm{m}$ and $42.7 \%$ $<63 \mu \mathrm{m})$, respectively. The tidal height of the 2 sampling sites was similar (ca. $2.3 \mathrm{~m}$ relative to hydrographic zero), with a mean duration of low-tide periods

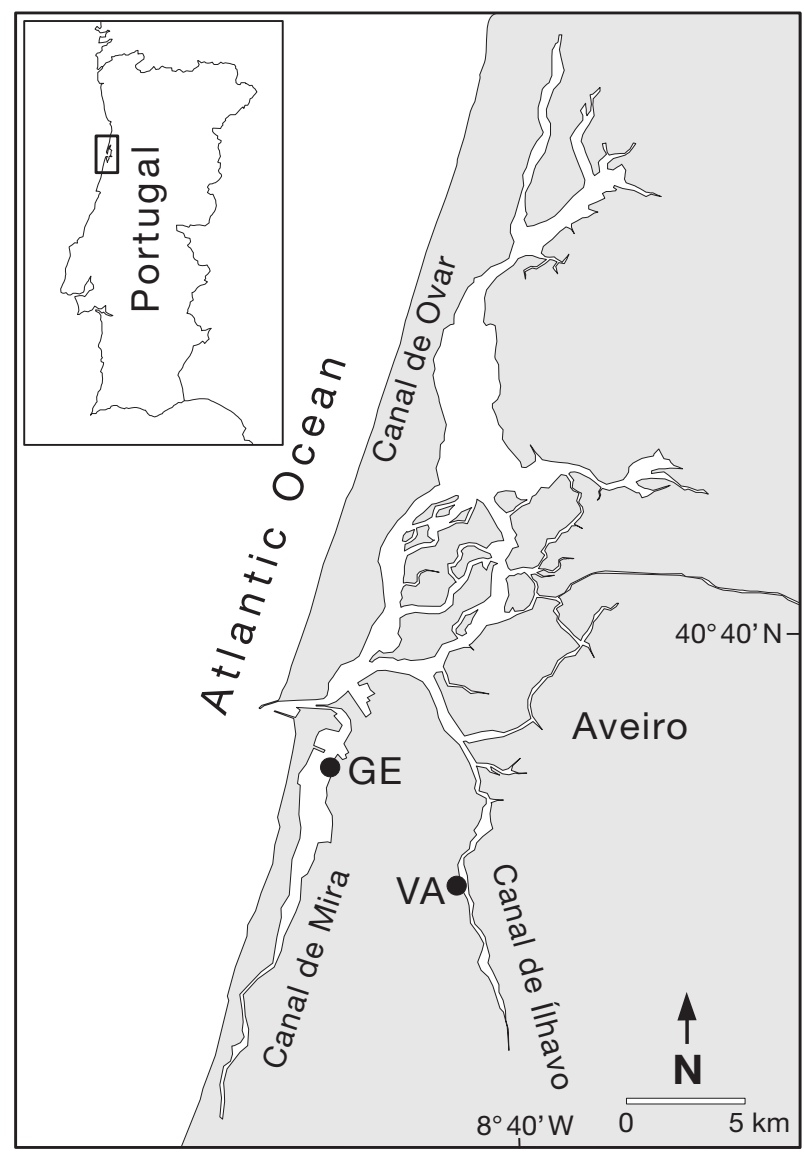

Fig. 1. Map of the Ria de Aveiro, Portugal, and location of the sampling sites Vista Alegre (VA) and Gafanha da Encarnação (GE) 
of ca. 8 h 30 min. Samples were collected during 5 spring-neap tidal cycles, distributed throughout 1 yr: 20 March to 6 April, 20 May to 6 June, 30 September to 16 October, 25 November to 13 December, and 10 to 26 February 2004. At each sampling site, samples were collected every $3 \mathrm{~d}$, resulting in the sampling of $6 \mathrm{~d}$ during each 14 d cycle. Sampling at VA and GE took place on consecutive days. Samples were collected once each sampling day, using plastic corers (19 mm inner diameter), and were taken to the laboratory, where they were maintained in an artificial tidal system until the measurements were carried out, on the next day. Sediment samples were sectioned with minimum disturbance into plastic rings $5 \mathrm{~mm}$ deep (same diameter of sampling corers), and maintained in a Petri dish containing filtered water
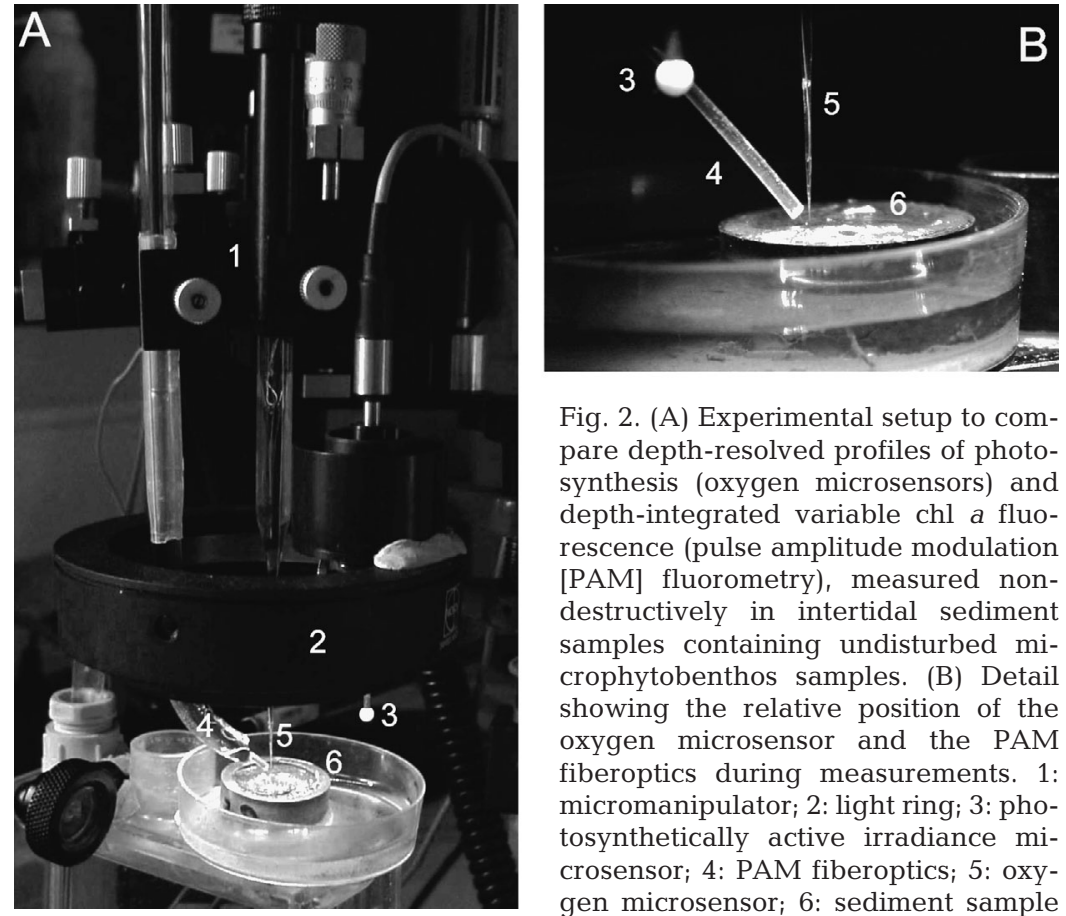

Fig. 2. (A) Experimental setup to compare depth-resolved profiles of photosynthesis (oxygen microsensors) and depth-integrated variable chl a fluorescence (pulse amplitude modulation [PAM] fluorometry), measured nondestructively in intertidal sediment samples containing undisturbed microphytobenthos samples. (B) Detail showing the relative position of the oxygen microsensor and the PAM fiberoptics during measurements. 1: micromanipulator; 2: light ring; 3: photosynthetically active irradiance microsensor; 4: PAM fiberoptics; 5: oxygen microsensor; 6: sediment sample were acclimated to a constant temperature of $20^{\circ} \mathrm{C}$ overnight, and all measurements were carried out at this temperature.

Photosynthesis measurements. Photosynthetic rates were measured using the 'light-dark shift' method of Revsbech \& Jørgensen (1983), by determining gross oxygen photosynthetic production using Clark-type amperometric oxygen microsensors with a built-in guard cathode and reference anode (OX25 model, 10 to $20 \mu \mathrm{m}$ tip, $90 \%$ response time $<0.5 \mathrm{~s}$; Unisense), connected to a picoammeter (PA2000, Unisense). The microsensor was positioned vertically within the sediment using a double-head micromanipulator (MM33, Märtzhäuser) controlled by an electrical motor (Oriel Encoder Mike and Oriel Model 18011 Controller, Oriel). The vertical position of the microsensor and the measurement of the photosynthetic rate at each depth were controlled using Sloper software (Unisense). Sediment samples were illuminated by cold white light provided by a halogen lamp (Volpi Intralux 5000-1, Volpi) and delivered to the sample by a fiberoptics bundle connected to a $5 \mathrm{~cm}$ diameter light ring (Standard Ringlight, Volpi), providing a homogeneous shade-free light field (Fig. 2A). During measurements, the sample was maintained below the centre of the light ring, at a fixed distance from it. Irradiance incident on the sample surface was measured continuously using a PAR microsensor (Spherical MicroQuantum Sensor US-SQS/W, Walz) positioned near the inner border of the light ring and connected to the fluorometer control unit (see below; Fig. 2B). The PAR sensor was calibrated to indicate the irradiance level at the sample surface. Vertical profiles of photosynthesis were obtained by measuring photosynthetic rates at depth intervals of $50 \mu \mathrm{m}$ until no response could be detected within the first $0.5 \mathrm{~s}$ after darkening. Vertical profiles were integrated over depth to obtain depth-integrated photosynthetic rates; the average values of these rates were compared with the correspondent fluorescence measurements.

Measurements made at adjacent depth intervals were assumed to be reasonably independent, on the basis of the comparable values of the standard diffusion distance of oxygen (Einstein-Smoluchowski equation) and of the vertical resolution applied (the criteria defined by Revsbech \& Jørgensen 1983). This could be expected due to the fast response time of the measuring system (90\% response time $<0.5 \mathrm{~s}$ ), which allowed us to measure the initial slope of the oxygen concentration decrease during a very short period (often $<1 \mathrm{~s}$ ) and the relatively low effective oxygen diffusion coefficient for fine sediments $\left(0.8 \times 10^{-5}\right.$ to $1.7 \times 10^{-5} \mathrm{~cm}^{2}$ $\mathrm{s}^{-1}$; Sweetrs et al. 1991). Vertical intervals of $50 \mu \mathrm{m}$ have been used in similar sediments or microalgal biofilms (e.g. Glud et al. 1992, Pinckney \& Zingmark 1993, Serôdio et al. 2001, Brotas et al. 2003).

Fluorescence measurements. Variable fluorescence was measured using a PAM fluorometer comprising a computer-operated PAM Control Unit (Walz) and an emitter-detector unit (WATER-EDF-Universal, Gademann Instruments). This instrument uses modulated blue light (LED-lamp peaking at $450 \mathrm{~nm}$, half-bandwidth of $20 \mathrm{~nm}$ ) as a source for measuring actinic and 
saturating light, emitted at a frequency of $18 \mathrm{~Hz}$ when measuring $F_{0}$, or $20 \mathrm{kHz}$ when measuring other fluorescence parameters (Serôdio 2004). Measurements were carried out using a $1.5 \mathrm{~mm}$ diameter plastic fibre, positioned at a constant distance of ca. $1 \mathrm{~mm}$, at a $45^{\circ}$ angle relative to the sample surface, pointing to the area where the tip of the oxygen microsensor contacted the sediment (Fig. 2B). The relative positions of microsensor and fiberoptics were maintained constant during measurements, as both were attached to the same double-head micromanipulator.

Comparison of photosynthesis and fluorescence. During periods matching daytime low tide at the sampling sites, paired measurements of photosynthesis and fluorescence were taken on the same sample each ca. 30 min. Before each set of measurements, the irradiance incident on the sample was set to match the irradiance measured outside and was kept constant for 15 to 20 min. PAR was continuously measured outside using a PAR sensor (LI-193SA and LI-250 light meter, Li-Cor) placed on the roof of the laboratory. After this period, and after confirming that photosynthesis had reached a steady-state (as monitored by $\mathrm{O}_{2}$ evolution near the surface), 1 photosynthesis profile was measured after which a saturating pulse was applied, determining $F_{\mathrm{s}}$ and $F_{\mathrm{m}}{ }^{\prime}$ and calculating $\Delta F / F_{\mathrm{m}}{ }^{\prime}$. The microsensor was moved to new position within the area monitored by the PAM fiberoptics (ca. $1.5 \mathrm{~mm}^{2}$ ), and a new pair of measurements was obtained. At each occasion, 5 replicated pairs of vertical profiles of photosynthesis and fluorescence parameters were determined. The actinic light was then switched off (other ambient actinic light levels were kept negligible), and saturating pulses were applied after $10 \mathrm{~s}$ and 2 and 5 min. Minimum $\left(F_{0}{ }^{0}, F_{0}^{2}, F_{0}^{5}\right)$ and maximum fluorescence $\left(F_{\mathrm{m}}{ }^{0}, F_{\mathrm{m}}{ }^{2}, F_{\mathrm{m}}{ }^{5}\right)$ values were determined for each time interval after darkening. The sample was then exposed to actinic light matching the new irradiance level measured outside. For simplicity, unless stated otherwise, $F_{0}$ and $F_{\mathrm{m}}$ represent measurements taken after 5 min dark adaptation $\left(F_{0}^{5}, F_{\mathrm{m}}{ }^{5}\right)$.

Fluorescence indices: Depth-integrated photosynthetic rates were compared to different fluorescence indices: ETR, EFY and EF, an index based solely on surface irradiance and minimum fluorescence level, calculated as $\mathrm{EF}=E \times F_{0}$. In the case of EFY and EF, photosynthetic rates were also compared to the values of the indices calculated using the fluorescence parameters $F_{\mathrm{s}}, F_{\mathrm{m}}$ ' and $F_{0}$, measured after $10 \mathrm{~s}$ and 2 min of dark adaptation $\left(F_{0}^{0}, F_{0}^{2}\right)$, and $F_{\mathrm{m}}$, measured after 0,2 and 5 min of dark adaptation $\left(F_{\mathrm{m}}{ }^{0}, F_{\mathrm{m}}{ }^{2}, F_{\mathrm{m}}{ }^{5}\right)$, instead of $F_{0}$. Fluorescence parameters $F_{0}, F_{\mathrm{s}}, F_{\mathrm{m}}$ ' and $F_{\mathrm{m}}$, were normalised to the fluorescence level measured on a fluorescence standard (Walz) using the same instrument settings.
Statistical analysis: Photosynthesis and fluorescence indices were compared using Type II linear regression, and slopes of linear regression equations were compared using the test for homogeneity of slopes (Sokal \& Rohlf 1981).

Microalgal identification. Microalgae were collected by placing 2 pieces of lens tissue on the surface of the sediment shortly after the beginning of diurnal low tide. After ca. $1 \mathrm{~h}$, the upper piece of lens tissue was removed and cells were resuspended in filtered seawater. Microalgal suspensions were fixed in $1 \% \mathrm{v} / \mathrm{v}$ formaldehyde and viewed using bright-field microscopy for determination of the relative abundance of major taxonomic groups (diatoms, euglenophytes and cyanobacteria). Diatom identification was carried out on subsamples oxidised using saturated potassium permanganate solution and digested in concentrated $\mathrm{HCl}$.

\section{RESULTS}

\section{Theoretical effects of depth integration}

The integration over depth has the general effect of attenuating the curvature of the light-response curves of both photosynthesis and the fluorescence index EFY (Fig. 3A,B). In the simplest case of a uniform vertical distribution of microalgal biomass, depth-integrated light-response curves appear not to saturate, or to saturate at higher irradiance levels, and to be less photoinhibited (decreased under high irradiance). In the case of photosynthesis (Fig. 3A), this is due to the contribution to the depth-integrated rates of increasingly deeper layers of sediment that become illuminated as irradiance at the surface increases. In the case of the fluorescence index (Fig. 3B), the difference between the light curves based on the product of depth-integrated parameters (EFY, Eq. 7) differs to those based on depth-resolved profiles (EFY, $z_{z, d}$ Eq. 6) due to the algebraical difference inherent to the 2 forms of calculation. As a consequence, despite the clear non-linearity of the relationship between photosynthesis and the fluorescence index when based on depth-specific, inherent parameters $\left(\mathrm{EFY}_{z}\right.$ vs. $\left.P_{z}\right)$, the resultant relationship between depth-integrated $P$ and EFY is virtually linear (Fig. 3C).

The effects of depth integration were found to depend strongly on the vertical distribution of microalgal biomass. Fig. 4 compares the relationship between photosynthesis and different fluorescence indices under a range of increasing irradiances for the different chl a vertical profiles. When photosynthesis is compared to the index ETR, which does not take into account the productive biomass, almost linear relationships are obtained for each chl a profile (Fig. 4B). 

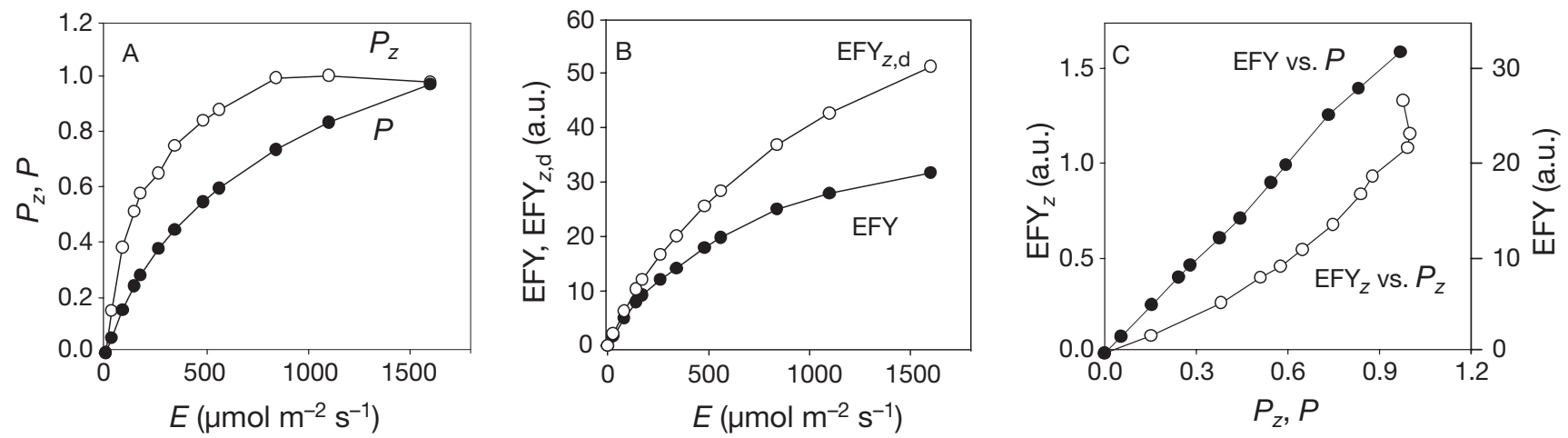

Fig. 3. Mathematical simulations showing the effects of depth integration. (A) Light response of inherent, depth-specific $\left(P_{z}\right)$ and depth-integrated $(P)$ photosynthetic rates (normalised to maximum values). (B) Light response of fluorescence index EFY as calculated from the depth integration of the depth-specific values of the index (EFY $\mathrm{z}_{\mathrm{d}, \mathrm{d}}$ Eq. 6) and calculated from depthintegrated parameters (EFY, Eq. 7). (C) Relationship between fluorescence index EFY as calculated on the basis of depth-specific $\left(E_{Z F}\right.$, Eq. 6) and of depth-integrated parameters (EFY, Eq. 7) and the depth-specific $\left(P_{z}\right)$ and depth-integrated photosynthetic rate $(P)$ (normalised to maximum values), respectively. Depth integration was based on uniform vertical profiles of chl a. See Table 1 for explanation of parameters. a.u.: arbitrary units

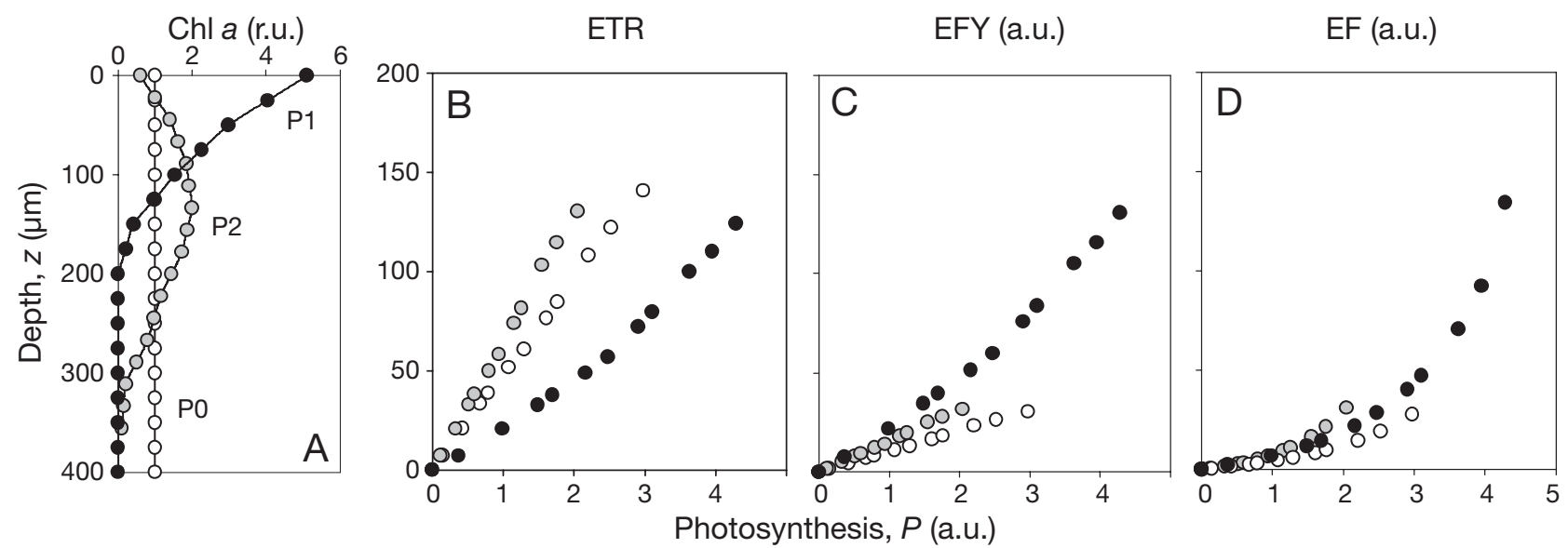

Fig. 4. Mathematical simulations showing the effects of the vertical distribution of microalgal biomass on the relationship between depth-integrated photosynthetic rates, $P$, and fluorescence indices ETR (B), EFY (C) and EF (D). Three different profiles of chl a (A) were used to simulate $P$ and the different fluorescence indices for the range of irradiance levels used in Fig. 3.

See Table 1 for explanation of parameters. r.u.: relative units; a.u.: arbitrary units

Changes in the biomass profile cause large variations in the slope of the linear trend, with the profile representing a subsurface chl a maximum (Profile P2) returning the highest ETR values. Considering the simultaneous changes in irradiance and biomass profile occurring during daytime low tides, these are likely to cause a large dispersion of data points and a low correlation between $P$ and ETR when measured on natural samples under in situ conditions. When productive biomass is considered, through the inclusion of the parameter $F_{0}$ in the index EFY, the relationship between EFY and $P$ also remains mostly linear, and changes in biomass profile continue to cause a large variability among the slopes of these linear trends (Fig. 4C). However, maximum index values are now obtained for the profile representing the chl a surface accumulation (P1). Fig. 4D also illustrates the use of the simplified index EF. Although a more curvilinear trend results for each biomass profile, particularly for Profile P1 under high irradiances, a lower dispersion of the data points is obtained when only low to moderate irradiances are considered.

\section{Photosynthesis versus fluorescence indices: diurnal variability}

The diurnal variability of the light response of depthintegrated photosynthesis is illustrated in Fig. 5. As predicted from the numerical simulations, photosynthetic rates were found to follow almost proportionally the hourly changes in incident irradiance, not exhibiting significant saturation, even under the highest irradiance levels (Fig. 5A,B). The absence of light satura- 

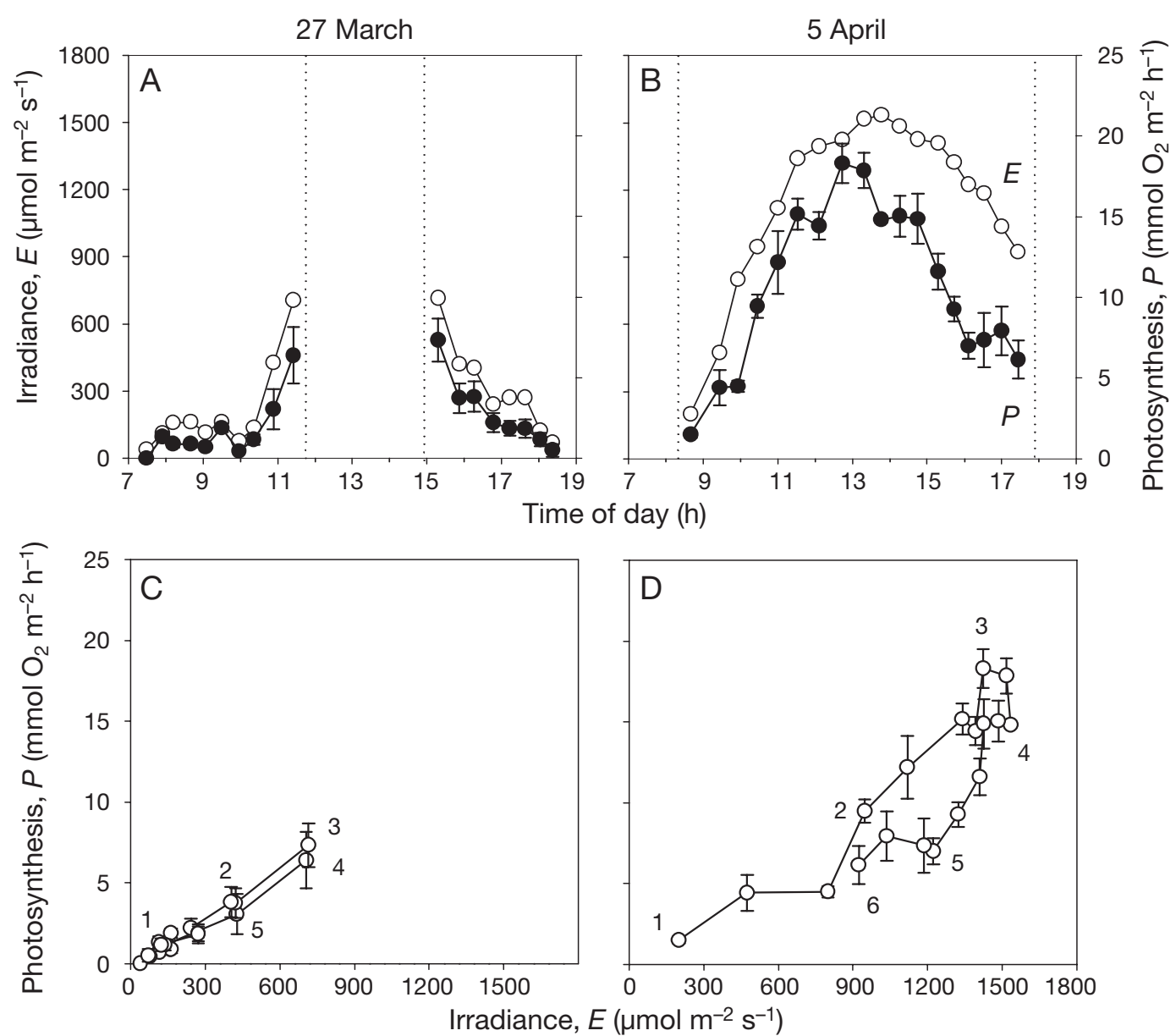

Fig. 5. Example of the hourly variation of surface irradiance, $E$, and depth-integrated photosynthetic rate, $P$, at the sampling site Vista Alegre (see Fig. 1), on 2 d along 1 spring-neap tidal cycle, (A,C) 27 March 2003 and (B,D) 5 April 2003. Vertical dotted lines indicate high tide. Numbers in (C) and (D) indicate the chronological order of the measurements. Error bars $= \pm 1 \mathrm{SE}$

tion is particularly evident when $P$ is plotted against $E$ (Fig. 5C,D), especially on 5 April, when samples were exposed to high irradiance levels (Fig. 5D). As with most days with long periods of exposure to high light during low tide, the light response of photosynthesis showed a clear hysteresis pattern, with $P / E$ values measured during the afternoon remaining consistently below the values observed during the morning period (Fig. 5D). The hourly variability of the photosynthetic light response also varied substantially among days, being strongly dependent on the light conditions during low tide and the timing of ebb and flood. This is exemplified on $27 \mathrm{March}$, when the fog occurring during most of the morning and the high-tide inundation during the middle of the day prevented the exposure to high light levels and reduced the daily dose of light exposure. As a result, no hysteresis was observed and, for comparable light levels, identical photosynthetic rates were observed during the morning and the afternoon low-tide periods.
The intraday variations in the photoresponse of photosynthesis were associated with changes in the vertical structure of productivity within the photic zone (Fig. 6). Vertical profiles of $P_{z}$ varied markedly along the light exposure periods, caused by changes in the vertical distribution of microalgal biomass due to migrations or to changes in the profiles $a^{*}{ }_{\mathrm{PAR}}$ or $\phi P$. Hourly changes in surface irradiance are not likely to have contributed to this variability, as irradiance remained saturating during most of the measuring period. Despite the large hourly and daily variability, on many days $P_{z}$ profiles presented maximum values clearly below the surface (50 to $100 \mu \mathrm{m})$ during the morning, and a monotonical decrease with depth, from maximum values at the surface, during the afternoon (Fig. 6).

This variation in the vertical distribution of photosynthesis is expected to affect the relationships between $P$ and ETR, EFY and EF, explaining the different abilities of these indices to trace changes in depth- 


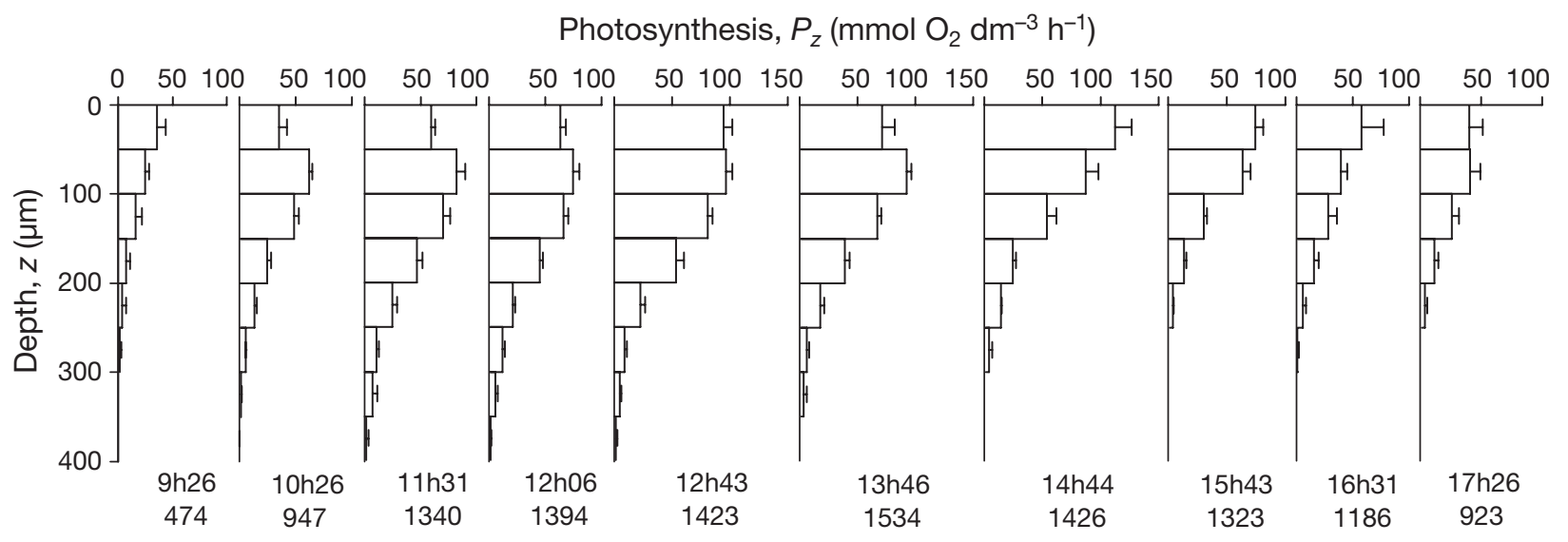

Fig. 6. Hourly variation of the vertical profile of photosynthesis during a daytime low-tide period (sampling site Vista Alegre, see Fig. 1, 5 April 2003). Error bars $= \pm 1$ SE. Number below time of day represents irradiance level at the surface $\left(\mu \mathrm{mol} \mathrm{m}^{-2} \mathrm{~s}^{-1}\right)$

integrated photosynthetic rates. In the case of ETR, although roughly following the overall pattern of hourly change of $P$, its variation throughout the day appears incapable of proportionally tracing $P$ along the higher end of its range of variation (Fig. 7A,B). This is particularly evident when plotting ETR against $P$, which results in a clearly non-linear, saturation-like pattern (Fig. 7C). This lack of correlation can be explained by the fact that ETR does not take into account changes in photosynthetic biomass or variations in the depth of the illuminated zone of the sediment. In contrast, EFY provides much better agreement with the variation of $P$. For the days 27 March and 5 April depicted in Fig. 7, EFY explains 87.2 and $86.1 \%$ of $P$ variability, respectively (Fig. 7D-F), despite the large experimental error associated with the measurement of photosynthesis using oxygen microsensors (using 5 replicated profiles, coefficient of variation was typically around $30 \%$ ). The relationship between EFY and $P$ was clearly linear, with highly significant correlations $(p<0.001)$ being found for the 2 days (Fig. 7F). When considering the whole dataset, significant correlations $(p<0.05)$ between EFY and $P$ were found for $94.3 \%$ of the days.

As exemplified in Fig. 7G-I, stronger correlations were often found when $P$ was compared to the simplified index EF. Considering the whole dataset, EF was found to correlate with $P$ better than EFY on $75.6 \%$ of the days. However, the use of EF resulted in only a slight improvement in the proportion of explained variability in $P$ : 5.8 and $3.7 \%$ for the 2 days illustrated in Fig. 7, and, 5.4\%, on average, for the whole dataset.
Table 2. Linear regression equations of fluorescence indices EF and EFY on photosynthetic rate $P(P=a \times \mathrm{EFY}+b)$ for the different sampling periods (spring-neap tidal cycles) and sampling sites (VA: Vista Alegre; GE: Gafanha da Encarnação). Statistical significance: ${ }^{* * *} \mathrm{p}<0.001,{ }^{*} \mathrm{p}<0.05$; sample size $(\mathrm{n})$

\begin{tabular}{|c|c|c|c|c|c|c|c|c|}
\hline \multirow{2}{*}{$\begin{array}{l}\text { Sampling } \\
\text { period }\end{array}$} & \multicolumn{4}{|c|}{ VA } & \multicolumn{4}{|c|}{$\mathrm{GE}-$} \\
\hline & $\mathrm{r}$ & $\mathrm{n}$ & a & $b$ & $\mathrm{r}$ & $\mathrm{n}$ & a & $b$ \\
\hline \multicolumn{9}{|l|}{ EF } \\
\hline Mar & $0.91^{* * *}$ & 85 & 18.92 & 4.9 & $0.83^{* * *}$ & 99 & 14.81 & 26.43 \\
\hline Jun & $0.66^{* * *}$ & 72 & 6.87 & 6.7 & $0.71^{* * *}$ & 26 & 3.21 & 27.99 \\
\hline Sep & $0.72^{* * *}$ & 80 & 6.33 & -3.9 & $0.76^{* * *}$ & 29 & 2.90 & 10.1 \\
\hline Nov & $0.72^{* * *}$ & 48 & 2.25 & 8.4 & $0.83^{* * *}$ & 35 & 1.68 & 7.37 \\
\hline Feb & $0.58^{* * *}$ & 46 & 2.25 & 2.8 & $0.78^{* * *}$ & 48 & 0.84 & 3.55 \\
\hline \multicolumn{9}{|l|}{ EFY } \\
\hline Mar & $0.87^{* * *}$ & 85 & 5.36 & 7.14 & $0.73^{* * *}$ & 99 & 4.61 & 13.77 \\
\hline Jun & $0.77^{* * *}$ & 72 & 1.55 & 15.44 & $0.69^{* * *}$ & 26 & 1.14 & 15.45 \\
\hline Sep & $0.69^{* * *}$ & 80 & 1.18 & -3.63 & $0.50^{*}$ & 29 & 0.58 & 2.94 \\
\hline Nov & $0.77^{* * *}$ & 48 & 0.63 & 4.19 & $0.90^{* * *}$ & 35 & 0.68 & 2.46 \\
\hline Feb & $0.58^{* * *}$ & 46 & 0.41 & 5.11 & $0.75^{* * *}$ & 48 & 0.18 & 1.74 \\
\hline
\end{tabular}

\section{Photosynthesis versus fluorescence indices: seasonal and spatial variability}

Despite the lack of significant correlations between the fluorescence index EFY and $P$ found on some days, highly significant correlations were generally obtained when data from different days within each $14 \mathrm{~d}$ cycle were pooled together $(p<0.001$ in all cases but one; Table 2). The slopes of the linear regression equations of EFY on $P$ were found to vary significantly among $14 \mathrm{~d}$ cycles, but not among sampling sites $(\mathrm{p}<0.001$ and $p=0.471$, respectively; test for homogeneity of slopes). This variation of the regression coefficients showed a marked seasonal trend, with the highest values being found in spring (March to April and May to June) and the lowest in winter (November and February).

This marked variation in the relationship between EFY and $P$ was not followed by substantial changes 

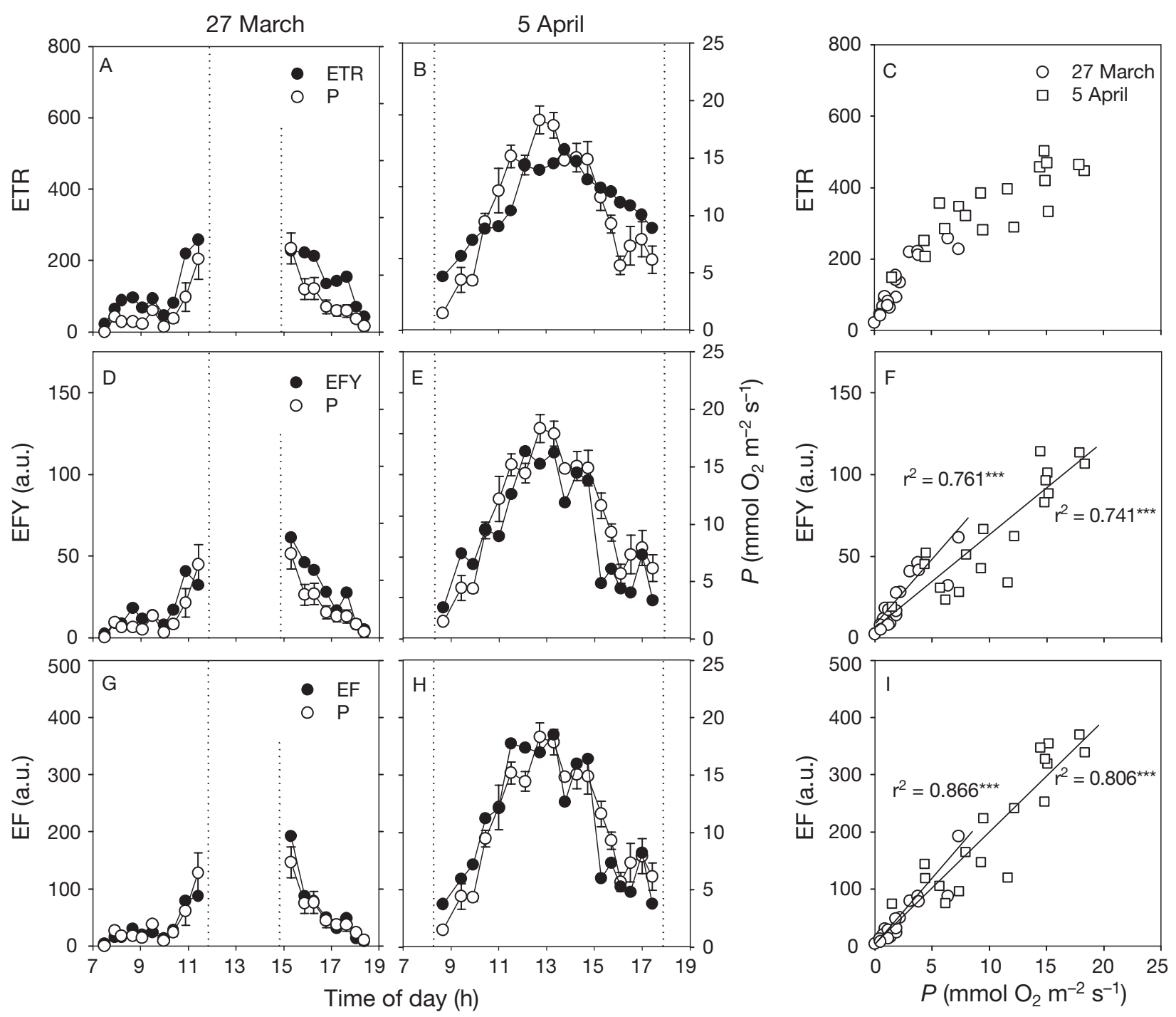

Fig. 7. Correlation between depth-integrated photosynthetic rates and fluorescence indices ETR (A-C), EFY (D-F) and EF (G-I) for 2 d during 1 spring-neap tidal cycle at the sampling site Vista Alegre (see Fig. 1), on (A,D,G) 27 March 2003 and $(\mathrm{B}, \mathrm{E}, \mathrm{H}) 5$ April 2003. Vertical dotted lines represent high tide. Error bars $= \pm 1 \mathrm{SE}$. ${ }^{* * *}$ : significant at $\mathrm{p}<0.001$

in the taxonomic composition of the microphytobenthos community. At both sampling sites, diatoms were always largely dominant throughout the year (relative abundance of euglenophytes and cyanobacteria in all cases $<1 \%$ ), with small changes at the genus level both within each spring-neap tidal cycle and at the seasonal time scale (Table 3). Navicula was, in all cases, the most abundant genus (presenting up to 5 species with relative abundances $>2 \%$ ), generally accounting for $>60$ and $40 \%$ of total cell counts in VA and GE, respectively. In VA, 70 to $95 \%$ of cell counts were accounted for by only 4 genera, Navicula, Nitzschia and Stauroneis being typically the most abundant, and the remaining genera accounting for $<2 \%$ each. In GE, a more even distri- bution of diatom taxa was found, with Cylindrotheca and Nitzschia being the second and third most abundant genera, and up to 6 genera presenting abundances $>2 \%$.

\section{Alternative fluorescence indices}

The use of fluorescence parameters other than $F_{0}$ resulted, for most of the tested parameters, in a reduction of the proportion of the variability in $P$ explained by EFY and weaker correlations between the 2 variables (Table 4). However, when EFY was calculated on the basis of $F_{0}{ }^{2}$, the variability in $P$ explained by EFY was generally increased (or had a negligible negative ef- 
fect) for most periods and for both sampling sites, either when considering each day separately or for pooled data. In contrast, fluorescence indices based on the parameter $F_{\mathrm{m}}$ (including $F_{\mathrm{m}}{ }^{\prime}$ ) resulted generally in much

Table 3. Seasonal variation of mean relative abundances (\%) of diatom genera of microphytobenthos assemblages for the 2 sampling sites (VA: Vista Alegre; GE: Gafanha da Encarnação). Mean values obtained by averaging the relative abundances for each day within each sampling period (spring-neap tidal cycle). Only abundances $>2 \%$ are presented. Relative abundances of other groups (euglenophytes and cyanobacteria) are $<1 \%$ in all cases

\begin{tabular}{|lccccc|}
\hline Genus & Mar & Jun & Sep & Nov & Feb \\
\hline VA & & & & & \\
Navicula & 65.6 & 26.6 & 59.8 & 67.1 & 60.3 \\
Nitzschia & 13.0 & 18.4 & 14.7 & 9.7 & 17.8 \\
Stauroneis & - & 21.4 & 7.5 & 8.1 & 16.2 \\
Cylindrotheca & - & 2.3 & - & - & - \\
Amphora & - & - & 5.9 & 5.5 & - \\
GE & & & & & \\
Navicula & 46.4 & 33.6 & 42.3 & 69.6 & 40.3 \\
Cylindrotheca & 7.1 & 24.8 & 3.2 & - & - \\
Nitzschia & 4.8 & 12.2 & 6.3 & 7.7 & 15.3 \\
Amphora & 4.2 & 8.1 & 5.6 & 7.2 & 3.3 \\
Parlibellus & - & - & 8.8 & - & 2.2 \\
Stauroneis & 4.1 & - & - & 2.7 & - \\
Achnanthes & 4.2 & - & - & - & 3.4 \\
\hline
\end{tabular}

Table 4. Variation in the variability in P explained by the index EFY when calculated using the indicated fluorescence parameters, relative to the variability obtained when using $F_{0}(\%)$. Mean daily variation for each sampling period, and results for the pooled data from each sampling period (within parentheses)

\begin{tabular}{|c|c|c|c|c|c|c|c|}
\hline $\begin{array}{l}\text { Sampling } \\
\text { period }\end{array}$ & $F_{0}^{0}$ & $F_{0}^{2}$ & $F_{\mathrm{S}}$ & $F_{\mathrm{m}}^{\prime}$ & $F_{\mathrm{m}}^{0}$ & $F_{\mathrm{m}}^{2}$ & $F_{\mathrm{m}}{ }^{5}$ \\
\hline \multicolumn{8}{|l|}{ VA } \\
\hline Mar & $\begin{array}{l}-3.7 \\
(-6.8)\end{array}$ & $\begin{array}{l}-0.7 \\
(-0.3)\end{array}$ & $\begin{array}{l}-9.8 \\
(-8.2)\end{array}$ & $\begin{array}{c}-35.1 \\
(-34.2)\end{array}$ & $\begin{array}{l}-37.0 \\
(-27.0)\end{array}$ & $\begin{array}{l}-18.1 \\
(-9.4)\end{array}$ & $\begin{array}{l}-17.5 \\
(-9.0)\end{array}$ \\
\hline Jun & $\begin{array}{c}0.5 \\
(14.9)\end{array}$ & $\begin{array}{c}2.2 \\
(-0.7)\end{array}$ & $\begin{array}{l}-21.8 \\
(-31.2)\end{array}$ & $\begin{array}{l}-26.7 \\
(-45.6)\end{array}$ & $\begin{array}{l}-12.7 \\
(-29.5)\end{array}$ & $\begin{array}{c}-4.6 \\
(-10.5)\end{array}$ & $\begin{array}{l}-2.4 \\
(-8.3)\end{array}$ \\
\hline Sep & $\begin{array}{c}5.8 \\
(2.9)\end{array}$ & $\begin{array}{c}6.2 \\
(7.8)\end{array}$ & $\begin{array}{l}-9.6 \\
(4.2)\end{array}$ & $\begin{array}{l}-34.6 \\
(-26.2)\end{array}$ & $\begin{array}{l}-23.3 \\
(-10.1)\end{array}$ & $\begin{array}{l}-24.7 \\
(-14.5)\end{array}$ & $\begin{array}{l}-18.1 \\
(-11.7)\end{array}$ \\
\hline Nov & $\begin{array}{c}2.9 \\
(-1.9)\end{array}$ & $\begin{array}{l}-0.2 \\
(2.6)\end{array}$ & $\begin{array}{c}5.6 \\
(-5.4)\end{array}$ & $\begin{array}{c}-27.9 \\
(-34.1)\end{array}$ & $\begin{array}{c}5.7 \\
(-16.0)\end{array}$ & $\begin{array}{c}1.4 \\
(-7.2)\end{array}$ & $\begin{array}{c}-0.3 \\
(-10.1)\end{array}$ \\
\hline Feb & $\begin{array}{l}-15.0 \\
(-49.0)\end{array}$ & $\begin{array}{l}-1.2 \\
(-4.1)\end{array}$ & $\begin{array}{l}-31.8 \\
(-58.0)\end{array}$ & $\begin{array}{l}-52.1 \\
(-93.4)\end{array}$ & $\begin{array}{c}-49.0 \\
(-92.4)\end{array}$ & $\begin{array}{l}-14.2 \\
(-35.6)\end{array}$ & $\begin{array}{l}-11.3 \\
(-25.1)\end{array}$ \\
\hline GE & & & & & & & \\
\hline Mar & $\begin{array}{c}-11.3 \\
(-17.1)\end{array}$ & $\begin{array}{c}3.0 \\
(0.5)\end{array}$ & $\begin{array}{l}-39.4 \\
(-13.9)\end{array}$ & $\begin{array}{l}-67.0 \\
(-85.1)\end{array}$ & $\begin{array}{l}-52.6 \\
(-30.4)\end{array}$ & $\begin{array}{l}-26.2 \\
(-10.7)\end{array}$ & $\begin{array}{l}-26.6 \\
(-10.0)\end{array}$ \\
\hline Jun & $\begin{array}{c}-11.6 \\
(6.2)\end{array}$ & $\begin{array}{c}2.1 \\
(6.0)\end{array}$ & $\begin{array}{l}-28.2 \\
(-78.1)\end{array}$ & $\begin{array}{l}-32.8 \\
(-78.3)\end{array}$ & $\begin{array}{c}-6.2 \\
(-42.4)\end{array}$ & $\begin{array}{c}1.1 \\
(29.4)\end{array}$ & $\begin{array}{c}1.8 \\
(30.9)\end{array}$ \\
\hline Sep & $\begin{array}{c}1.3 \\
(39.6)\end{array}$ & $\begin{array}{c}18.1 \\
(18.0)\end{array}$ & $\begin{array}{l}-36.9 \\
(-18.2)\end{array}$ & $\begin{array}{l}-52.8 \\
(-20.1)\end{array}$ & $\begin{array}{c}-39.6 \\
(1.3)\end{array}$ & $\begin{array}{c}-39.1 \\
(0.2)\end{array}$ & $\begin{array}{l}-55.2 \\
(-6.3)\end{array}$ \\
\hline Nov & $\begin{array}{c}2.2 \\
(-0.3)\end{array}$ & $\begin{array}{c}0.2 \\
(-0.3)\end{array}$ & $\begin{array}{c}2.2 \\
(-8.0)\end{array}$ & $\begin{array}{c}-5.9 \\
(-17.6)\end{array}$ & $\begin{array}{c}-6.7 \\
(-13.8)\end{array}$ & $\begin{array}{c}-3.4 \\
(-12.6)\end{array}$ & $\begin{array}{c}-3.9 \\
(-14.2)\end{array}$ \\
\hline Feb & $\begin{array}{c}-7.1 \\
(-21.9)\end{array}$ & $\begin{array}{l}-0.4 \\
(5.0)\end{array}$ & $\begin{array}{l}-34.9 \\
(-75.8)\end{array}$ & $\begin{array}{c}-44.5 \\
(-109.3)\end{array}$ & $\begin{array}{l}-26.5 \\
(-91.5)\end{array}$ & $\begin{array}{c}-4.0 \\
(-25.9)\end{array}$ & $\begin{array}{c}-2.4 \\
(-21.9)\end{array}$ \\
\hline
\end{tabular}

weaker correlations with $P$, despite some exceptions (June, GE). Intermediate results were obtained for fluorescence parameters requiring a very short $\left(F_{0}^{0}\right)$ or no dark adaptation $\left(F_{\mathrm{s}}\right)$, causing moderate reduction in the correlation between EFY and $P$, which, however, remained statistically significant in most cases. The same trend was obtained when these alternative fluorescence parameters were used to compute the index EF.

\section{DISCUSSION}

\section{Fluorescence versus photosynthesis in microphytobenthos}

The use of variable chl a fluorescence to estimate rates of photosynthesis by undisturbed microphytobenthos assemblages has been shown to depend on 2 types of factors. Firstly, the physiological relationship between the effective quantum yield of PSII, $\Delta F / F_{\mathrm{m}}{ }^{\prime}$, and the quantum yield of photosynthesis, $\phi P$, which is affected by a diverse number of processes such as transfer of excitation energy from PSII to PSI, cyclic electron flow around PSII, fluorescence emission by PSI, or PSII heterogeneity (Falkowski et al. 1986, Schreiber et al. 1995b, Geel et al. 1997, Flameling \& Kromkamp 1998, Hartig et al. 1998, Franklin \& Badger 2001). In the case of $\phi P$ being based on carbon fixation or net oxygen evolution measurements, processes like the cyclic electron transport around PSI, pseudocyclic electron transport (Mehler reaction), photorespiration, or mitochondrial respiration (Weger et al. 1989, Raven \& Johnston 1991, Glud et al. 1992, Flameling \& Kromkamp 1998) must also be considered. While most of these factors are common to higher plants and most algal groups, the $\Delta F / F_{\mathrm{m}}{ }^{\prime}$ versus $\phi P$ relationship in microphytobenthos may be further complicated by the influence of species- or group-specific factors that can affect differently the various microalgal taxa that compose natural sedimentary biofilms at any particular moment. These include pigment composition, absorption cross-section of PSII and occurrence of state transitions (Büchel \& Wilhelm 1993, Schreiber et al. 1995b, Geel et al. 1997, Flameling \& Kromkamp 1998, Gilbert et al. 2000, Masojídek et al. 2001).

Secondly, the estimation of photosynthetic rates from fluorescence mea- 
surements depends on the variability in productive biomass that, by affecting the light absorption efficiency of the assemblage, can cause important changes in photosynthetic rate independently from $\Delta F / F_{\mathrm{m}}{ }^{\prime}$ or $\phi P$ (Serôdio et al. 2001). Unlike the more common cases when light absorption efficiency can be taken as constant (microalgal suspensions, macroalgal thalli, plant leaves), for microphytobenthos this factor may be the dominant process determining photosynthetic rates and represent a major source of discrepancy between fluorescence indices and photosynthetic rates on short time scales (Serôdio 2003). The use of $F_{0}$ to account for the variability in photosynthesis due to changes in productive biomass, based on a linear relationship between the 2 quantities, is also dependent on various group-specific factors like the absorption cross-section of solar and exciting light (mostly determined by pigment composition), the vertical profile of biomass and light absorption efficiency (related to migratory behaviour), and the attenuation of incident light (solar and exciting) and of emitted fluorescence within the assemblage (Serôdio et al. 1997, 2001, Honeywill et al. 2002).

\section{Depth-integration effects}

Whilst the factors affecting the relationship between $\Delta F / F_{\mathrm{m}}{ }^{\prime}$ and $\phi P$ and between $F_{0}$ and productive biomass have been previously identified (discussed in detail elsewhere; Serôdio 2003), the results of the present study showed that the use of variable fluorescence to estimate photosynthetic rates is additionally conditioned by the depth-integrated nature of the fluorescence parameters measured on undisturbed samples. This results from the combined effects of (1) light attenuation and depth integration of fluorescence parameters used to calculate $\Delta F / F_{\mathrm{m}}{ }^{\prime}$, causing it to differ from the inherent PSII quantum yield of microalgae (Forster \& Kromkamp 2004, Serôdio 2004), and (2) the algebraical difference between the value of the index EFY calculated on the basis of the depth-specific (Eq. 6) and depth-integrated (Eq. 7 ) terms $F_{0}$ and $\Delta F / F_{\mathrm{m}}{ }^{\prime}$.

The results of numerical simulations have shown that integration over depth of photosynthetic rates and of the index EFY contribute to linearise the relationship between the 2 variables. This result was obtained even when the inherent light response of both EFY and $P$ differed markedly from each other. Similar results were obtained by Forster \& Kromkamp (2004), and may help to explain the linear relationship found for sediments, when non-linearities could be expected to occur more frequently (Serôdio 2003, present study). However, when variations in the vertical distribution of biomass were simulated, important departures from linearity were predicted, indicating that the EFY versus $P$ relationship may be strongly affected by factors that control the vertical migratory movements of microalgae, such as surface irradiance, desiccation, and timing of flood/ebb or sunrise/sunset (Serôdio et al. 2006). Interestingly, the results of numerical simulations showed that, except for the case of large accumulation of biomass at the surface under high irradiances, a lower dispersion of data points and stronger correlations may be found when $P$ is compared to the simplified index EF (compared to EFY).

The modelling approach of the present study was based on 2 main assumptions: (1) that both photosynthesis and fluorescence emission are under steadystate conditions when the measurements are taken, and (2) that attenuation of light (actinic and measuring light and emitted fluorescence) in the photic zone is mainly dependent on sediment characteristics and constant over changes in the microalgal concentration. The first assumption is justified by the fact that samples were allowed to acclimate to constant irradiance levels (15 to $20 \mathrm{~min}$ ), and that the steady state in photosynthesis (oxygen evolution) and fluorescence emission $\left(F_{\mathrm{s}}\right)$ was confirmed before each pair of measurements was obtained. Regarding the second assumption, the alternative approach of considering light attenuation as a function of microalgal vertical distribution has been shown to yield similar results, particularly regarding the linearisation of the relationship between depth-integrated photosynthesis and fluorescence (Forster \& Kromkamp 2004). In fact, the model seems to have captured the essential features of the system, as its predictions were generally matched by experimental data.

\section{Diurnal variability}

The main results of numerical simulations were generally confirmed experimentally regarding the patterns of diurnal variability of EFY and $P$. The hourly variation of the vertical distribution of photosynthetic activity (photosynthetic light absorption and quantum yield) and the depth integration of fluorescence signals caused significant effects on the integrated photosynthetic light-response of the microalgal layer measured at the sediment surface. These effects were particularly notable on days when samples were exposed to high irradiance for long periods, resulting in hysteresis patterns in the photosynthetic response to surface irradiance. Under these conditions, depth-integrated photosynthesis varies independently from irradiance, due to the changes in the factors that determine the vertical structure of productivity within the photic zone (Eq. 1), $a^{*}{ }_{\text {PAR }} \phi P$, 
$C$ (associated to vertical migration of motile microalgae), or light attenuation (e.g. following the compacting of sediment due to desiccation). The decrease in $a^{*}{ }_{\text {PAR }}$ and $\phi P$ may result from photoprotective processes, related to the operation of the xanthophyll cycle, or from photoinhibitory effects of excessive light, causing the rate of photodamage to the photosynthetic apparatus to exceed the rate of the operation of repair processes (Müller et al. 2001). Other potential causes include the decrease in nutrient or $\mathrm{CO}_{2}$ availability, the increase in photorespiration due to $\mathrm{O}_{2}$ accumulation in the photic zone, and changes in photosynthetic activity associated to endogenous rhythms (Falkowski et al. 1985, Ludden et al. 1985, Glud et al. 1992, Levy et al. 2004).

Short-term changes in the vertical profile of productivity are expected to increase the discrepancy between EFY and $P$, as it accentuates the differences between the fluorescence index based on depthintegrated parameters and the photosynthetic rate, obtained from depth-specific measurements. However, the experimental data have shown that the natural variability of the vertical distribution of productivity is sufficiently low to allow EFY to closely trace variations in $P$, and for significant linear relationships between EFY and $P$ to be found in the large majority of cases. This indicates that, at least for hourly time scales ( $<1 \mathrm{~d}$ ), the product of $F_{0}$ and $\Delta F / F_{\mathrm{m}}{ }^{\prime}$ is an adequate proxy for the combined depth profile of photosynthetic light absorption efficiency $\left(a^{*}{ }_{\text {PAR }}\right.$ and $c$ ) and quantum yield of photosynthesis, $\phi P$.

Also in agreement with the results of numerical simulations, $P$ was found to correlate better with the simplified index EF than with EFY in some cases. Considering that the theoretical model predicted a departure from linearity in the case of biomass profiles, with a steep decrease below the surface formed under high irradiances (Fig. 4D), this result may be explained by high light-induced downward migration of microalgae (Kingston 1999, Serôdio et al. 2006). This photoprotective behaviour has been demonstrated to occur for irradiances $>500 \mu \mathrm{mol} \mathrm{m} \mathrm{m}^{-2} \mathrm{~s}^{-1}$ for samples collected at Sampling Site VA (Serôdio et al. 2006), and would prevent the large accumulation of biomass at the surface (P1-like profile; Fig. 4), yielding more vertically homogenous biomass profiles. This hypothesis is supported by the hourly variation of the vertical profiles of photosynthesis that typically do not show evidence of large accumulation of biomass at the surface under high irradiances (Fig. 6). Nevertheless, the improvement in predictive ability provided by EF is, when present, very reduced, and does not seem to justify its use as an alternative to EFY, considering the loss of information on physiological processes this would represent.

\section{Seasonal and spatial variability}

The fluorescence index EFY proved to be a good predictor of photosynthetic rates in a wide range of conditions, covering the natural variability in incident light, vertical distribution of productivity, sediment characteristics (e.g. granulometry, affecting desiccation and water content during low tide and light penetration) and taxonomic composition of the microalgae assemblage. However, the regression coeffi- cients of EFY on $P$ were found to vary significantly during the year, among the sampled spring-neap tidal cycles, although not among sampling sites. This parameter is of practical interest to estimate $P$ from EFY, and its large seasonal variability indicates that it is not possible to define a single conversion factor that is applicable all year round. Similar seasonal variability in the relationship between photosynthetic rates and fluorescence indices was found for intertidal microphytobenthos of the Tagus estuary (Serôdio 2003), contradicting the findings of Barranguet \& Kromkamp (2000), which indicated the possibility to use a single conversion factor valid throughout the year.

This variation in the slope of the EFY versus $P$ relationship seemed unrelated to seasonal changes in taxonomic composition of the sedimentary biofilms, considering the low variability observed down to the genus level, and the inexistence of differences among the regression slopes for VA and GE when the variability in taxon composition between the 2 sites was comparable (or larger) to the variability verified among the sampled $14 \mathrm{~d}$ cycles. However, by collecting only 1 lens tissue sample per day, intraday variations in species composition of the biofilm (Perkins et al. 2002) could have passed unnoticed. Moreover, due to the selectivity of the lens tissue technique, nonmotile species may not have been accounted for either.

A more likely explanation is a change in the photoacclimation status of the microalgae, following the seasonal variation in light conditions. Changes in the relative values of $a^{*}{ }_{\text {PAR }}$ or $a^{*}{ }_{\text {ML }}$ (e.g. due to changes in photosynthetic pigment composition), altering the emission of $F_{0}$ per unit of chl $a$, or changes in the relationship between $\Delta F / F_{\mathrm{m}}{ }^{\prime}$ and $\phi P$, could have contributed to the variation in the slope of the regression of EFY on $P$. These factors, however, may not fully explain the overall variation observed in the EFY versus $P$ relationship, which is probably also caused by changes in the vertical distribution of biomass or to methodological errors (see below).

Because all measurements were carried out under constant temperature, the present results cannot be readily generalised to conditions under which the microalgae may suffer large changes in temperature, as during low-tide periods. Temperature is likely to 
affect the carbon metabolism activity independently of the initial steps of photosynthesis (which determine fluorescence emission) and thus introduce variability in the $\phi F$ versus $\phi P$ relationship. However, the existing evidence indicates that, at least for estuarine benthic diatoms, short-term changes in temperature do not significantly affect the relationship between ETR and the photosynthetic rate (Morris \& Kromkamp 2003).

\section{Application}

The use of fluorescence-based methods in the estimation of rates of photosynthesis by microphytobenthos requires the determination of conversion factors that may enable the conversion of fluorescence indices based on arbitrary units (Barranguet \& Kromkamp 2000, Morris \& Kromkamp 2003, Serôdio 2003). The observed temporal variability in the linear relationship between EFY and $P$ implies that conversion factors must be determined prior to each application, although they may remain valid for up to one $14 \mathrm{~d}$ cycle.

The results obtained regarding the use of different fluorescence parameters as proxies for the productive biomass indicate that $F_{0}^{2}$ may be considered as an advantageous alternative to $F_{0}$. While allowing the same (or better) predictive ability as $F_{0}, F_{0}^{2}$ is less time consuming and less intrusive, therefore appearing preferable to minimise artefactual effects on microalgal migratory behaviour.

The variation in the regression coefficients of EFY on $P$ observed among sampling periods could have also been caused by methodological factors affecting the determination of $F_{0}$ independently of biological factors. Particularly when measured on intact sediment samples, the value of $F_{0}$ (or any other fluorescence parameter considered individually) depends on various aspects of the experimental setup such as fiberoptic characteristics, measurement geometry (relative position between the fibre and the sample), and instrument settings. Despite the efforts made to control these factors (normalisation to fluorescence standard, reduction of measurement area), variations in the experimental setup may have contributed to the observed variability. In this context, it may be suggested that the estimation of the productive biomass by absolute fluorescence parameters could be advantageously replaced by proxies for chl a that are based on the ratio of independent measurements, thus virtually independent of instrument settings and distance to the sample surface. One possibility is the normalised difference vegetation index (NDVI, Rouse et al. 1973), an optically based index that allows non-destructive estimation of the chl $a$ content of the photic zone of the sediment (Forster \& Jesus 2006, Kromkamp et al. 2006, Serôdio et al. 2006).
Acknowledgements. We thank Sónia Cruz for assistance in field and laboratory work. This work was supported by project POCTI/MAR/15318/99, funded by Fundação para a Ciência e a Tecnologia. We thank 2 anonymous reviewers for critical comments on the manuscript.

\section{LITERATURE CITED}

Barranguet C, Kromkamp J (2000) Estimating primary production rates from photosynthetic electron transport in estuarine microphytobenthos. Mar Ecol Prog Ser 204: $39-52$

Brotas V, Risgaard-Petersen N, Ottosen L, Serôdio J, Ribeiro L, Dalsgaard T (2003) In situ measurement of photosynthetic activity and respiration of intertidal benthic microalgal communities undergoing vertical migration. Ophelia $57: 13-26$

Büchel C, Wilhelm C (1993) In vivo analysis of slow chlorophyll fluorescence induction kinetics in algae: progress, problems and perspectives. Photochem Photobiol 58: 137-148

Falkowski PG, Dubinsky Z, Wyman K (1985) Growth-irradiance relationships in phytoplankton. Limnol Oceanogr 30: 311-321

Falkowski PG, Wyman K, Ley AC, Mauzerall DC (1986) Relationship of steady-state photosynthesis to fluorescence in eukaryotic microalgae. Biochim Biophys Acta 849: 183-192

Flameling IA, Kromkamp J (1998) Light dependence of quantum yield for PSII charge separation and oxygen evolution in eukaryotic algae. Limnol Oceanogr 43:284-297

Forster RM, Jesus B (2006) Field spectroscopy of estuarine intertidal habitats. Int J Remote Sens 27:3657-3669

Forster RM, Kromkamp J (2004) Modelling the effects of chlorophyll fluorescence from subsurface layers on photosynthetic efficiency measurements in microphytobenthic algae. Mar Ecol Prog Ser 284:9-22

Franklin LA, Badger MR (2001) A comparison of photosynthetic electron transport rates in macroalgae measured by pulse amplitude modulated chlorophyll fluorometry and mass spectrometry. J Phycol 37:756-767

Geel C, Versluis W, Snel JFH (1997) Estimation of oxygen evolution by marine phytoplankton from measurements of efficiency of photosystem II electron flow. Photosynth Res 51:61-70

Genty B, Briantais JM, Baker NR (1989) The relationship between the quantum yield of photosynthetic electron transport and quenching of chlorophyll fluorescence. Biochim Biophys Acta 990:87-92

Gilbert M, Wilhelm C, Richter M (2000) Bio-optical modelling of oxygen evolution using in vivo fluorescence: comparison of measured and calculated photosynthesis/irradiance (P-I) curves in four representative phytoplankton species. J Plant Physiol 157:307-314

Glud RN, Ramsing NB, Revsbech NP (1992) Photosynthesis and photosynthesis-coupled respiration in natural biofilms quantified with oxygen microsensors. J Phycol 28: $51-60$

Hartig P, Wolfstein K, Lippemeier S, Colijn F (1998) Photosynthetic activity of natural microphytobenthos populations measured by fluorescence (PAM) and ${ }^{14} \mathrm{C}$-tracer methods: a comparison. Mar Ecol Prog Ser 166:53-62

Honeywill C, Paterson DM, Hagerthey SE (2002) Determination of microphytobenthic biomass using pulse-amplitude modulated minimum fluorescence. Eur J Phycol 37: 485-492 
Kingston MB (1999) Effect of light on vertical migration and photosynthesis of Euglena proxima (Euglenophyta). J Phycol 35:245-253

Kromkamp J, Barranguet C, Peene J (1998) Determination of microphytobenthos PSII quantum efficiency and photosynthetic activity by means of variable chlorophyll fluorescence. Mar Ecol Prog Ser 162:45-55

Kromkamp JC, Morris EP, Forster RM, Honeywill C, Hagerthey S, Paterson DM (2006) Relationship of intertidal surface sediment chlorophyll concentration to hyperspectral reflectance and chlorophyll fluorescence. Estuaries Coasts 29:183-196

Levy O, Dubinsky Z, Schneider K, Achituv Y, Zakai D, Gorbunov MY (2004) Diurnal hysteresis in coral photosynthesis. Mar Ecol Prog Ser 268:105-117

Ludden E, Admiraal W, Colijn F (1985) Cycling of carbon and oxygen in layers of marine microphytes - a simulation model and its eco-physiological implications. Oecologia 66:50-59

Masojídek J, Grobbelaar JU, Pechar L, Koblízek M (2001) Photosystem II electron transport rates and oxygen production in natural waterbloom of freshwater cyanobacteria during a diel cycle. J Plankton Res 23:57-66

Morris EP, Kromkamp JC (2003) Influence of temperature on the relationship between oxygen- and fluorescence-based estimates of photosynthetic parameters in marine benthic diatom (Cylindrotheca closterium). Eur J Phycol 38:133-142

Müller P, Li XP, Niyogi KK (2001) Non-photochemical quenching. A response to excess light energy. Plant Physiol 125:1558-1566

Perkins RG, Oxborough K, Hanlon ARM, Underwood GJC, Baker NR (2002) Can fluorescence be used to estimate the rate of photosynthetic electron transport within microphytobenthic biofilms? Mar Ecol Prog Ser 228:47-56

Pinckney J, Zingmark R (1993) Photophysiological responses of intertidal benthic microalgal communities to light environments. Limnol Oceanogr 38:1373-1383

Raven JA, Johnston AM (1991) Mechanisms of inorganiccarbon acquisition in marine phytoplankton and their implications for the use of other resources. Limnol Oceanogr 36:1701-1714

Revsbech NP, Jørgensen BB (1983) Photosynthesis of benthic microflora measured with high spatial resolution by the oxygen microprofile method: capabilities and limitations of the method. Limnol Oceanogr 28:749-756

Rouse JW, Haas RH, Schell JA, Deering DW (1973) Monitoring vegetation systems in the great plains with ERTS. In: Third Earth Resources Technology Satellite Symposium, NASA SP-351, Vol 1. NASA, Washington, DC, p 309-317

Editorial responsibility: Rutger de Wit, Montpellier, France
Schreiber U, Schliwa U, Bilger W (1986) Continuous recording of photochemical and nonphotochemical chlorophyll fluorescence quenching with a new type of modulation fluorometer. Photosynth Res 10:51-62

Schreiber U, Hormann H, Neubauer C, Klughammer C (1995a) Assessment of photosystem quantum yield by chlorophyll fluorescence quenching analysis. Aust J Plant Physiol 22:209-220

Schreiber U, Endo T, Mi HL, Asada K (1995b) Quenching analysis of chlorophyll fluorescence by saturation pulse method: particular aspects relating to the study of eukaryotic algae and cyanobacteria. Plant Cell Physiol 36: $873-882$

Serôdio J (2003) A chlorophyll fluorescence index to estimate short-term rates of photosynthesis by intertidal microphytobenthos. J Phycol 39:33-46

Serôdio J (2004) Analysis of variable chlorophyll fluorescence in microphytobenthos assemblages: implications of the use of depth-integrated measurements. Aquat Microb Ecol 36:137-152

Serôdio J, Marques da Silva J, Catarino F (1997) Nondestructive tracing of migratory rhythms of intertidal microalgae using in vivo chlorophyll a fluorescence. J Phycol 33: $542-553$

Serôdio J, Marques da Silva J, Catarino F (1998) Relationship between chlorophyll fluorescence quenching and $\mathrm{O}_{2}$ evolution in microalgae. In: Garab G (ed) Photosynthesis: mechanisms and effects, Vol V. Kluwer Academic Publishers, Dordrecht, p 4109-4112

Serôdio J, Marques da Silva J, Catarino F (2001) Use of in vivo chlorophyll a fluorescence to quantify short-term variations in the productive biomass of intertidal microphytobenthos. Mar Ecol Prog Ser 218:45-61

Serôdio J, Coelho H, Vieira S, Cruz S (2006) Microphytobenthos vertical migratory photoresponse as characterised by light-response curves of surface biomass. Estuar Coast Shelf Sci 68:547-556

Sokal RR, Rohlf FJ (1981) Biometry. WH Freeman, New York

Sweerts JPRA, Kelly CA, Rudd JWM, Hesslein R, Cappenberg TE (1991) Similarity of whole-sediment molecular diffusion coefficients in freshwater sediments of low and high porosity. Limnol Oceanogr 36:335-342

Underwood GJC, Kromkamp J (1999) Primary production by phytoplankton and microphytobenthos in estuaries. Adv Ecol Res 29:93-153

Weger HG, Herzig R, Falkowski PG, Turpin DH (1989) Respiration losses in the light in a marine diatom: measurements by short-term mass spectrometry. Limnol Oceanogr 34:1153-1161

Submitted: January 26, 2007; Accepted: July 12, 2007

Proofs received from author(s): September 9, 2007 